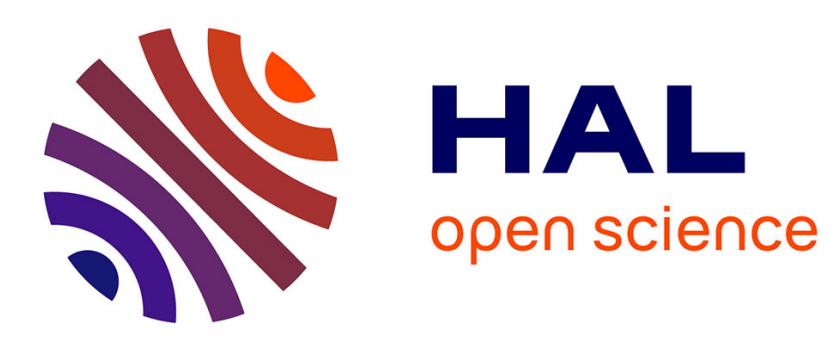

\title{
Monitoring the non-specific interactions of catechin through diffusion measurements based on pulsed-field gradients
}

\author{
C. Monteiro, C. Maechling, C. Herve Du Penhoat
}

\section{- To cite this version:}

C. Monteiro, C. Maechling, C. Herve Du Penhoat. Monitoring the non-specific interactions of catechin through diffusion measurements based on pulsed-field gradients. Magnetic Resonance in Chemistry, 2002, pp.S110-S114. hal-00307293

\section{HAL Id: hal-00307293 \\ https://hal.science/hal-00307293}

Submitted on 29 Jul 2008

HAL is a multi-disciplinary open access archive for the deposit and dissemination of scientific research documents, whether they are published or not. The documents may come from teaching and research institutions in France or abroad, or from public or private research centers.
L'archive ouverte pluridisciplinaire HAL, est destinée au dépôt et à la diffusion de documents scientifiques de niveau recherche, publiés ou non, émanant des établissements d'enseignement et de recherche français ou étrangers, des laboratoires publics ou privés. 


\title{
Monitoring the non-specific interactions of catechin through diffusion measurements based on pulsed-field gradients
}

\author{
C. Monteiro ${ }^{1}$, C. Maechling ${ }^{2}$ and C. Hervé du Penhoat ${ }^{1}$ \\ 1 Centre de Recherches sur les Macromolécules Végétales, CNRS, BP 53, 38041 Grenoble Cedex 9, France \\ 2 Laboratoire de Pharmacochimie de la Communication Cellulaire, UMR 7081 CNRS/UniversitéLouis Pasteur, Facultéde Pharmacie, 74 \\ route du Rhin, BP 24, 67401 Illkirch Cedex, France
}

The self-association of aqueous catechin as a function of concentration was monitored through variationsin $1 \mathrm{H}$ chemical shifts, proton $T_{1}$ and $T_{2}$ data and translational diffusion coefficients obtained with the pulsed-field gradient spin-echo method. The latter approach is very efficient and it is not restricted to aromatic compounds. Equilibrium constants were estimated for various models of self-association and the apparent enthalpy of dissociation was measured with isothermal titration calorimetry. Comparison of the latter parameter with thermodynamic data reported for various types of non-specific interactions suggests that such phenomena could be studied using this approach.

\section{INTRODUCTION}

Non-specific interactions play a major role in the aggregation phenomena that govern the physical state of molecular mixtures. This is particularly true of plant extracts where control of colloid formation and/or precipitation is a major industrial concern. Althoughmuch effort has been devoted to devising NMRexperiments for studying specific interactions such as ligand binding, non-specific interactions have received less attention 1,2. The aggregation phenomena of surfactants 3,4, nucleotides 5,6, caffeine 7,8, polyphenol s8-13 and aromatic drug molécules 14-16 and the non-specific stacking interactions of caffeine with methyl gallate 8, polyphenols with peptides 10,13,17 and aroma substances12 are notable exceptions. The majority of these NMR studies of self- or hetero-association involve aromatic compounds and have relied on chemical shift titration versus concentration to quantify the equilibrium constants 7,12,14-16. However, in several cases no significant chemical shift variations were observed in spite of the detection of line broadening and/or intermolecular NOEs that indicated hetero-association 13,16,17 .

For many types of molecules, where non-specific interactions are not expected to produce significant chemical shift changes, monitoring variations in molecular motion (either rotational18 or translational diffusion 3-6) would seem to be an attractive alternative.Measurement of self-diffusion coefficients is rapid19,20 and prediction of the variations in translational motion on the basis of hydrodynamic theory21 is straightforward as long as themolecules arewell represented by the Stokes-Einstein-Debye model ('stick regime') 22. In this work, the self-association of catechin was studied to explore the feasibility of such an approach.

Catechin (2,3-trans) and epicatechin (2,3-cis) (Fig. 1) are the basic monomeric units of condensed tannins which are ubiquitous secondary metabolites of higher plants. Tannins are thought to participate in plant defense by rendering the tissues of leaves, bark and fruit unpalatable for herbivores and omnivores. These polyphenols display a strong propensity to form complexes with other biomolecules such as proteins, polysaccharides and alkaloids. This phenomenon is responsible for the astringency (precipitation of salivary proteins) and poor nutritional quality (irreversible complexation of gut enzymes and dietary proteins, inhibition of iron absorption) of polyphenol-rich foods 10.The dimerization of catechin in silico has afforded both parallel and anti-parallel orientations of the target molécules 23 corroborating the nonspecific nature of catechin self-association.

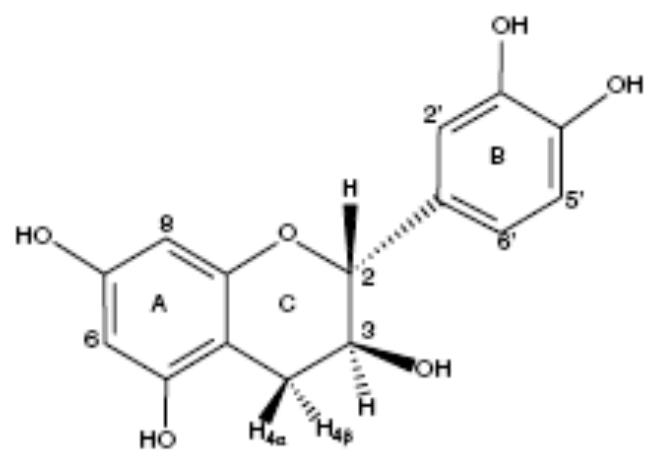

Figure 1. Structure of catechin with atom numbering 


\section{RESULTS AND DISCUSSION}

Chemical shift titrations of catechin as a function of concentration have been investigated previously11,12 and selfassociation constants $\left(4.3<K_{\mathrm{a}}<7.4\right)$ were established from the latter data for the isodesmic model.12 This model of solute self-association is based on the assumption that the solute molecules associate to form stacks (dimers, trimers, etc.) with an equilibrium constant, Ka, that is the same for each step. This leads to simple expressions for the fractional populations of the various species as a function of the monomer concentration [C1] and Ka:

$$
\begin{aligned}
& \mathrm{C}_{1}+\mathrm{C}_{1} \rightleftharpoons \mathrm{C}_{2} \quad\left[\mathrm{C}_{2}\right]=\mathrm{K}_{\mathrm{a}} \times\left[\mathrm{C}_{1}\right]^{2} \\
& \mathrm{C}_{1}+\mathrm{C}_{2} \rightleftharpoons \mathrm{C}_{3} \quad\left[\mathrm{C}_{3}\right]=\mathrm{K}_{\mathrm{a}}^{2} \times\left[\mathrm{C}_{1}\right]^{3} \\
& \mathrm{C}_{1}+\mathrm{C}_{\mathrm{E}-1} \rightleftharpoons \mathrm{C}_{n} \quad\left[\mathrm{C}_{\mathrm{E}}\right]=K_{\mathrm{a}}^{\mathrm{E}-1} \times\left[\mathrm{C}_{1}\right]^{n}
\end{aligned}
$$

The limiting value of the Taylor series for the sum of the fractional populations yields the following expression for the total concentration $\left[\mathrm{C}_{0}\right]$ as long as the product $K_{a} \times\left[C_{1}\right]$ is $<1$ :

$$
\left[\mathrm{C}_{0}\right]=\left[\mathrm{C}_{1} \mathrm{l} /\left(1-\mathrm{K}_{\mathrm{a}} \times\left[\mathrm{C}_{1}\right)^{2}\right.\right.
$$

A single chemical shift is observed for each spin, indicating that the various species are undergoing fast exchange. As the distances between vertically stacked molecules are in the 3-4 $\AA$ range and the ring current magnetic field giving the main contribution to nuclear shielding decreases rapidly with the distance $\left(\sim 1 / r_{3}\right)$, it is assumed that the upfield chemical shifts on complexation are due only to the influence of the neighboring molecule (within the limits of this model of molecular association all such contributions are assumed to be equal). The chemical shift of the $C_{n}$ species and the chemical shift dependence on concentration for the isodesmic model are given by Eqs (5) and (6), respectively 14 :

$$
\begin{aligned}
\delta_{\mathrm{C}_{\mathrm{n}}}= & \left\{(n-1) \delta_{\max }+\delta \mathrm{C}_{\mathrm{l}}\right\} / n \\
\delta_{\mathrm{cbs}}-\delta_{\mathrm{C}_{1}}= & \left(\Delta \delta_{\max }\right)\left(\left\{2 K_{\mathrm{a}}\left[\mathrm{C}_{0}\right]+1\right.\right. \\
& \left.\left.-\sqrt{ }\left(4 K_{\mathrm{a}}\left[\mathrm{C}_{0}\right]+1\right)\right\} / 2 K_{\mathrm{a}}\left[\mathrm{C}_{0}\right]\right)
\end{aligned}
$$

A very similar expression is obtained for the dependence of dobs on concentration in the case of dimerization 14:

$$
\left.\delta_{\mathrm{cbs}}-\delta_{\mathrm{C}_{\mathrm{j}}}=\left(\Delta \delta_{\max }\right)\left(\left\{4 K_{\mathrm{d}}\left[\mathrm{C}_{0}\right]+1-\sqrt{(} 8 K_{\mathrm{d}}\left[\mathrm{C}_{0}\right]+1\right)\right\} / 4 K_{\mathrm{d}}\left[\mathrm{C}_{0}\right]\right)
$$

If it is assumed that each successive stack of the catechin monomer affords the same decrease in $D$ obst, $\Delta D_{\mathrm{t}}$, the dependence of Dobs t on total concentration will be analogous to that of the chemical shifts for both the isodesmic (Eq 6) and dimerization (Eq 7) models.

${ }_{1} \mathrm{H}$ NMR chemical shifts of catechin as a function of [ $\left.\mathrm{C}_{0}\right]$ are given in Table 1 . The $\mathrm{H}-3, \mathrm{H}-4 \alpha$ and $\mathrm{H}-4 \beta$ signals display the most significant variations in $\delta$ obs with increasing concentration. $\Delta \delta$ max and $K_{a}$ values were calculated by leastsquares minimization of the experimental data ( $\left.\delta_{o b s} \_\delta_{c 1}\right)$ with respect to the theoretical values in Eqs (6) and (7) using the simplex method 24 and the modeled data are given in Table 2.

\begin{tabular}{|l|l|l|l|l|l|l|l|l|l|l|}
\hline Spin & 2.3 & 4.6 & 8.0 & 11.5 & 17.2 & 23.0 & 27.6 & 34.4 & 41.3 & 45.9 \\
\hline $\mathrm{H}-2$ & $-\mathrm{c}$ & $-\mathrm{c}$ & $-\mathrm{c}$ & $-\mathrm{c}$ & $-\mathrm{c}$ & 4.77 & 4.77 & 4.73 & 4.73 & 4.74 \\
\hline $\mathrm{H}-3$ & 4.28 & 4.28 & 4.28 & 4.27 & 4.27 & 4.23 & 4.23 & 4.23 & 4.23 & 4.20 \\
\hline $\mathrm{H}-4 \mathrm{a}$ & 2.90 & 2.90 & 2.90 & 2.90 & 2.90 & 2.89 & 2.88 & 2.89 & 2.88 & 2.87 \\
\hline $\mathrm{H}-4 \mathrm{~b}$ & 2.58 & 2.58 & 2.58 & 2.58 & 2.58 & 2.55 & 2.55 & 2.54 & 2.54 & 2.52 \\
\hline $\mathrm{H}-20$ & 6.89 & 6.89 & 6.89 & 6.89 & 6.89 & 6.88 & 6.89 & 6.88 & 6.88 & 6.86 \\
\hline
\end{tabular}

Table 1. $1 \mathrm{H}$ NMR chemical shifts in (vobs, $\mathrm{ppm}$ ) for various concentrations of catechina Catechin concentration (mM)

\footnotetext{
a Catechin (Sigma) was added to $1.75 \mathrm{mM}$ solutions of acetic acid (SDS, purex $99.8 \%$ ) in D2O to afford solutions (0.75 $\mathrm{ml}$ ) containing the above total concentrations, [CO]. Both the HOD and acetic acid methyl signals were evaluated as internal references for the chemical shifts $(\delta H O D=4.800 \mathrm{ppm}$ was the internal standard for the data given above).

b See Fig. 1 for the numbering.

c Overlapping with the HOD signal.
} 


\begin{tabular}{|c|c|c|c|}
\hline $\begin{array}{l}\text { Experimental } \\
\text { probe }\end{array}$ & $\begin{array}{l}\text { Self- } \\
\text { association } \\
\text { model }\end{array}$ & $K_{\Delta}\left(M^{-1}\right)$ & $\begin{array}{l}\text { Simulated values of } \\
\Delta \delta_{\max }(\mathrm{ppm}) \\
\text { or } \Delta D_{t}\left(\mathrm{~cm}^{2} \mathrm{~s}^{-1}\right)\end{array}$ \\
\hline \multirow[t]{2}{*}{$\delta_{c b a} \mathrm{H}-3$} & I & $47 \pm 2$ & -0.42 \\
\hline & D & $2.0 \pm 0.8$ & -0.50 \\
\hline \multirow[t]{2}{*}{$\delta_{\text {oba }} \mathrm{H}-4 \alpha$} & I & $2.0 \pm 0.8$ & -0.30 \\
\hline & D & $1.0 \pm 0.9$ & -0.18 \\
\hline \multirow[t]{2}{*}{$\delta_{c k} \mathrm{H}-4 \beta$} & I & $3.2 \pm 0.9$ & -0.33 \\
\hline & D & $2.3 \pm 1.3$ & -0.31 \\
\hline \multirow[t]{2}{*}{$D_{t}^{\mathrm{ska}} \mathrm{H}-\mathrm{z}$} & I & $8 \pm 4.5$ & $-6.7 \times 10^{-6}$ \\
\hline & D & $8.5 \pm 4$ & $-4.4 \times 10^{-6}$ \\
\hline
\end{tabular}

Table 2. Self-association constants of catechin, Ka, for isodesmic (I) and dimerization (D) models

The average value of $\mathrm{Ka}_{\mathrm{a}}\left(3.3 \mathrm{M}^{-1}\right.$ using all of the data for $\mathrm{H}-3, \mathrm{H}-4$, and $\left.\mathrm{H}-4 \beta\right)$ is slightly lower than the average value $\left(5.6 \mathrm{M}^{-1}\right)$ reported by Dufour and Bayonove 12 for catechin dissolved in $\mathrm{D}_{2} \mathrm{O}-\mathrm{H}_{2} \mathrm{O}-$ ethanol- $d_{6}(8$ $: 1: 1)$ but the spread in Ka parameters $( \pm 50 \%)$ for the various spins is very similar. Comparison of the chemical shifts of the acetic acid methyl moiety with respect to those of the HOD resonance for the 10 samples listed in Table 1 yields an average value of $2.084 \pm 0.008 \mathrm{ppm}$ in spite of a digital resolution of \pm 0.001 ppm. Unfortunately, in the present case, it is not feasible to acquire data for a much larger range of concentrations owing to the poor signalto- noise ratio at lower concentrations and precipitation at higher concentrations. Hence it is difficult to improve the convergence of data from chemical shift titrations and the adjustable parameter $\Delta \delta \max$ cannot be used to validate the simulations as it is not easily calculated.
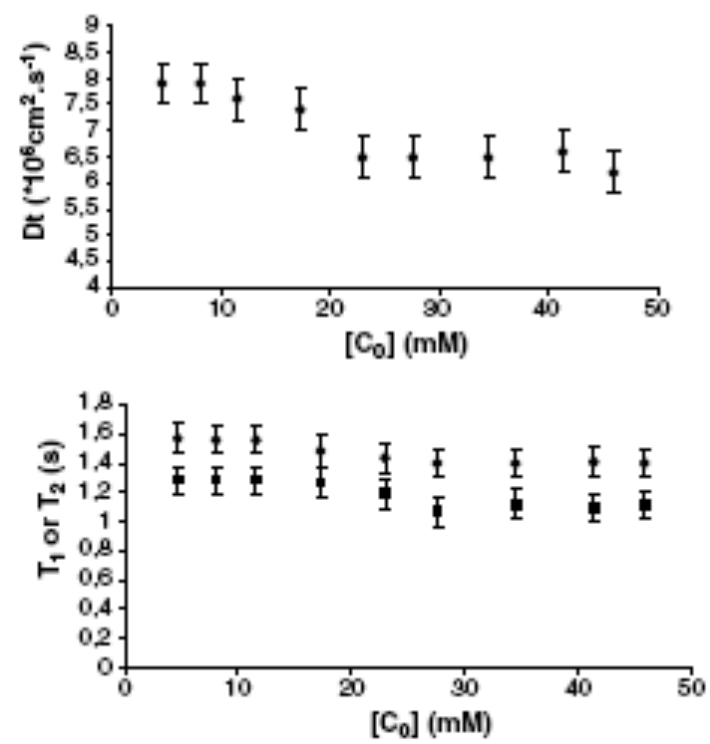

Figure 2. Plots of $T_{1}(\downarrow), T_{2}(\square)$ and $D$ t for various total concentrations of catechin measured at $298 \mathrm{~K}$ and $400 \mathrm{MHz}$.

Experimental error bars are indicated.

Plots of $T_{1}, T_{2}$ and $D_{\mathrm{t}}$ as a function of concentration are shown in Fig. 2. The error bars for $T_{1}$ and $T_{2}$ are as large as the variations in the relaxation parameters, suggesting that rotational dynamics are not sufficiently modulated by association phenomena when the target molecules are of similar size. In contrast, more readily detectable variations in $D_{\mathrm{t}}$ indicate that translational diffusion is a better probe of the non-specific interactions of medium-sized molecules. In favorable cases, the experimental precision of $D_{\mathrm{t}}$ measurements is about $1 \% 19,20$ and standard deviations of $0.05 \times 10^{-6} \mathrm{~cm}^{2} \mathrm{~s}^{-1}$ have been obtained from the attenuation of anomeric signals of carbohydrates $(1<\mathrm{DP}<10) 25$ or from the B-ring signal (isolated singlets) of galloylated tannins. Owing to deuterium exchange with the solvent, the intensity of the catechin H-6 and H-8 singlets 
evolved with time. Therefore, the attenuation of the H-2' signal was used to establish the $D^{\text {obs }}$ t values, but its intensity could not be evaluated with precision owing to the nearby H-5' and H-6' multiplets (the high-field H-3, $\mathrm{H}-4$ ، and $\mathrm{H}-4^{\vee}$ signals were even less suitable owing to phase distortion induced by J-modulation during the echo sequence), with the result that standard deviations for $D^{\text {obs }}$ t were almost an order of magnitude larger $( \pm 0.4 \mathrm{x}$ $10^{-6} \mathrm{~cm}^{2} \mathrm{~s}^{-1}$ ) than those referred to above.AKa value of $\sim 8 \mathrm{M}_{-} 1$ was obtained by leastsquares minimization for both isodesmic and dimerization models of self-association.

The $D^{\text {obs }}$ t coefficient of $7.9 \times 10^{-6} \mathrm{~cm}^{2} \mathrm{~s}^{-1}$ for the most dilute solution is much higher than the value of $3.6 \times 10^{-6}$ $\mathrm{cm}^{2} \mathrm{~s}^{-1}$ predicted on the basis of hydrodynamic theory21 (molecular models of catechin could be assimilated to a cylinder $14 \AA$ in length with a radius of $3.8 \AA$ ), indicating that a microviscosity correction factor, $f$, of 0.45 would be necessary. The simulation protocol afforded $\Delta D$ t values of $-6.7 \times 10 \_6$ and $-4.4 \times 10^{-6} \mathrm{~cm}^{2} \mathrm{~s}^{-1}$ for the $^{-10}$ isodesmic and dimerization models of self-association, respectively. As the catechinmonomerdoes not obey the Stokes-Einstein-Debye model, it is not possible to predict this adjustable parameter accurately. However, upper and lower limits for the microviscosity factor are known $(0.45<f<1.0)$ and the $D_{\mathrm{t}}$ value for the dimer $\left(1.2 \times 10 \_6 \mathrm{~cm}_{2} \mathrm{~s}_{-} 1\right)$ that can be extrapolated from the $\Delta D_{\mathrm{t}}$ parameter of the isodesmicmodel is clearly too low (with $f=1.0$ this would correspond to a sphere of radius $16.6 \AA$, where $D_{\mathrm{t}}=k T / 6 \_f r 0$ ), whereas that of the dimerization model $\left(3.5 \times 10^{-6} \mathrm{~cm}^{2} \mathrm{~s}^{-1}\right)$ is reasonable.

A plot of the apparent enthalpy of dilution as a function of catechin concentration is shown in Fig. 3. Dissociation is endothermic and can be detected even at the lowest concentration (open squares). The apparent molar enthalpy of dilution $(6.5 \mathrm{~kJ}$ mol_1 $)$ includes both dilution and dissociation contributions and has not been treated quantitatively in this study.26 Plots of theoretical monomer and dimer fractional populations (\%) for both the isodesmic and dimerization models as a function of total catechin concentration are displayed in Fig. 4. The Ka value estimated from the translational diffusion profile (8 M_1) was used to establish the fractional [ $\left.\mathrm{C}_{1}\right]$ and $\left[\mathrm{C}_{2}\right]$ populations. For both models of self-association, the predicted dimer population of the $2.3 \mathrm{mM}$ sample is compatible with the reduced $(3 / 410 \%$ of that of a $23 \mathrm{~mm}$ solution) apparent enthalpy of dilution that is observed experimentally. It appears that dimerization is followed by precipitation without significant accumulation of aggregates higher than dimers.

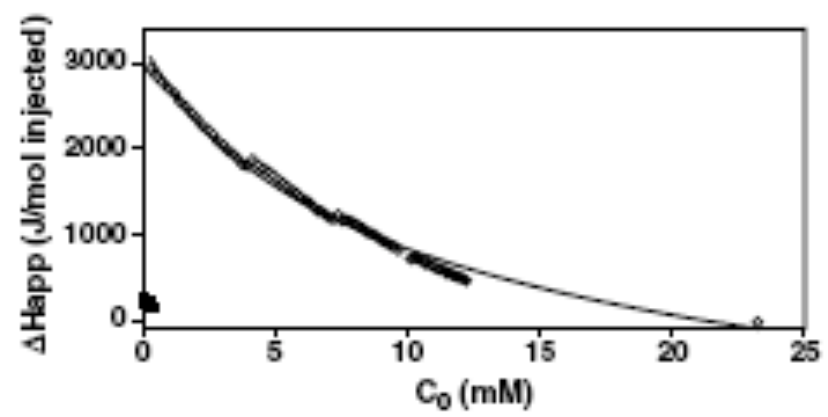

Figure 3. Plots of the apparent enthalpy change $\left(\mathrm{J} \mathrm{mol}^{-1}\right)$ on diluting aqueous solutions of catechin $[2.3 \mathrm{mM}(\square)$ and $23.3 \mathrm{mM}(\bigcirc)$ ] versus total catechin concentration [CO] in the cell.

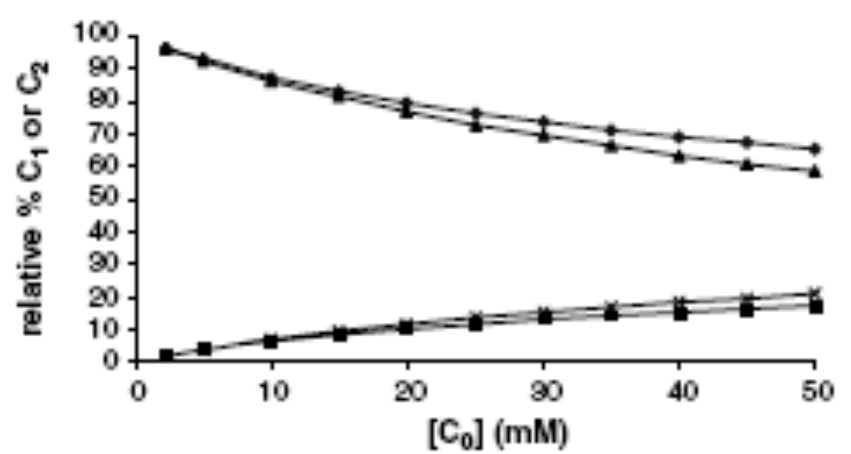

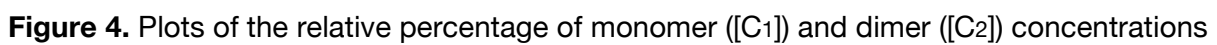
as a function of the total concentration $([\mathrm{Co}])$ of catechin for both dimerization $(\boldsymbol{\nabla}, \mathrm{x})$ and isodesmic $(\boldsymbol{\square}, \mathbf{\Delta})$ models characterized by an equilibrium constant, $\mathrm{Ka}$, of 8 . 
In conclusion, it has been demonstrated that selfassociation of catechin can be monitored with translational diffusion measurements based on the pulsed-field gradient spin-echo method. The thermodynamic data for various non-specific interactions involving sugars (carbohydrate- surfactant and carbohydrate-carbohydrate interactions) has been reviewed recently 27 and comparison with results from the present work suggests that these systems should be amenable to study using translational diffusion measurements. In favorable cases (isolated NMR signals), the association constants should be more accurately defined than those obtained from chemical shift titrations and this approach is not limited to aromatic molecules. An added advantage of the $D_{\mathrm{t}}$ approach, in the case of moderately sized molecules (for example, tetrasaccharides 25 ), is that $D_{\mathrm{t}}$ can be related to the dimensions of the molecular assembly. As pointed out be a referee, other data treatment such as biexponential fitting 20 associated with the BPPLED pulse sequence 28 (here the composite pulses provide selfcompensation of induced eddy currents) might be useful for extracting the diffusion coefficients of the monomers and the dimers.

\section{EXPERIMENTAL}

\section{Sample preparation}

Various amounts of catechin (Sigma) were added to $1.75 \mathrm{~mm}$ solutions of acetic acid (SDS, purex 99.8\%) in $\mathrm{D}_{2} \mathrm{O}$ to afford solutions $(0.75 \mathrm{ml})$ containing the total concentrations, $\left[\mathrm{C}_{0}\right]$ indicated in Table 1 . The NMR tubes were sealed under argon after vacuum removal of dissolved oxygen.

\section{Isothermal titration calorimetry}

Calorimetric data were obtained using a VP-ITCmicrocalorimeter (MicroCal, USA). Experiments were performed at $298 \mathrm{~K}$. Solutions were degassed under vacuum just prior to the experiment. Aliquots of $15 \mu \mathrm{l}$ of catechin solution were automatically injected from a microsyringe at 5 min intervals into the sample cell $(1.4192 \mathrm{ml})$ containing acetic acid solution.Efficientmixing of the solutionwas achievedby a paddle on the end of the syringe rotated at constant speed ( $310 \mathrm{rpm})$. The power versus time plot shows a peak as heat is absorbed upon equilibrium displacement by dilution, and then returns to baseline as thermal equilibrium is reached. The area under the peaks gives the amount of heat absorbed. The data were analysed using Microcal Origin software 29,30.

\section{NMR}

$1 \mathrm{H}$ NMR pulsed-gradient spin-echo experiments were conducted on a Bruker Avance 400 spectrometer at $298 \mathrm{~K}$. The stimulated spin-echo sequences1 was used to measure the translational self-diffusion coefficients as described previously.25 The gradient duration $(\delta)$ was varied from 1 to $20 \mathrm{~ms}$ while keeping its strength fixed at $9.15 \mathrm{G} \mathrm{cm}^{-1}$. The intergradient delay $(\Delta)$ and gradient recovery delay were $5 \mathrm{~ms}$ and $50 \mu \mathrm{s}$, respectively. The translational self-diffusion coefficients were obtained by fitting the intensities of the H-2' signal in spectra acquired with various lengths of the gradient pulses (8-15 data points) to the StejskalTanner equation with inhouse software :

$$
\begin{aligned}
M= & 1 / 2 M_{0} \exp \left\{-\left(\tau_{2}-\tau_{1}\right) / T_{1}-2 \tau_{1} / T_{2}\right. \\
& \left.-\left(\tau_{1} G \gamma\right)^{2} D_{t}\left[\tau_{2}-\left(\tau_{1} / 3\right)\right]\right\}
\end{aligned}
$$

All experiments were run at least four times. Spin-lattice relaxation times were measured with the inversion-recovery sequence. The recycle time was greater than $6 x T 1$ and data were collected for 10-20 $\tau$ values which varied from $5 \mathrm{~ms}$ to $2 \times T_{1}$. Spin-spin relaxation times were obtained with the Carr-PurcellMeiboom-Gill sequence and data were collected for roughly 20 spectrawith various numbers of echos (total echo duration, $2 n \tau$, varied from $2 \mathrm{~ms}$ to $1 \mathrm{~s})$. The integrals of the peaks were fitted to a three- $\left(T_{1}\right)$ or two- $\left(T_{2}\right)$ parameter exponential function using spectrometer system software and inhouse software, respectively, and all relaxation experiments were also run at least twice. 


\section{REFERENCES}

1. $\quad$ Martire DE. Anal. Chem. 1974; 46: 1712.

2. Lamberty W, Stamm H, Stafe J. J. Phys. Chem. 1983; 87: 1589.

3. Stilbs P. Prog. Nucl. Magn. Reson. Spectrosc. 1986; $19: 1$.

4. Lindman B, Olsson U, Soderman O. In Dynamics of Solutions and Fluid Mixtures by NMR, Delpuech J-J (ed.). Wiley: Chichester, 1995; 345-395.

5. Stilbs P, Stokkeland I. Biophys. Chem. 1985; 22: 65.

6. Stilbs P, Rymd'en R. Biophys. Chem. 1985; 22: 145.

7. $\quad$ Lilley TH, Linsdell H, Maestre A. J. Chem. Soc., Faraday Trans. 1992; 88: 2865.

8. Baxter NJ, Williamson MP, Lilley TH, Haslam E. J. Chem. Soc., Faraday Trans. 1996; 92: 231.

9. Spencer CM, Cai Y,Martin R, Lilley TH, Haslam E. J. Chem. Soc., Perkin Trans. 2 1990; 651.

10. Baxter NJ, Lilley TH, Haslam E, Williamson MP. Biochemistry 1997; 36: 5566.

11. Mirabel M, Glories Y, Pianet I, Dufourc EJ. J. Chim. Phys. Phys.- Chim. Biol. 1999; 96: 1629.

12. Dufour C, Bayonove CL. J. Agric. Food Chem. 1999; 47: 678.

13. Hatano T, Yoshida T, Hemingway RW. In Plant Polyphenols 2: Chemistry, Biology, Pharmacology, Ecology, Gross GG,Hemingway RW, Yoshida T (eds). Kluwer Academic/Plenum Publishers: New York, 1999; 509-526.

14. Davies DB, Djimant LN, Veselkov AN. J. Chem. Soc., Faraday Trans. 1996; 92: 383.

15. Davies DB,Veselkov DA, Evstigneev MP,Veselkov AN. J. Chem. Soc., Perkin Trans. 2 2001; 61.

16. Swierzewski R, Poznanski J, Golankiewicz B, ZielenkiewiczW. J. Mol. Liq. 2002; 95: 339.

17. Hatano T, Hemingway RW. J. Chem. Soc., Chem. Commun. 1996; 2537.

18. Verdier L, Gharbi-Benarous J, Bertho G, Evrard-Todeshi N, Mauvais P, Girault J-P. J. Chem. Soc., Perkin Trans. 2 2000; 2363.

19. Stilbs P. Prog. Nucl. Magn. Reson. Spectrosc. 1987; 19: 1.

20. Johnson CS Jr. Prog. Nucl. Magn. Reson. Spectrosc. 1999; 34: 203.

21. de la Torre JG, Bloomfield VA. Q. Rev. Biophys. 1981; 14: 81.

22. Boer'e RT, Kidd RG. Annu. Rep. NMR Spectrosc. 1982; 13: 319.

23. Tobiason FL, Hemingway RW, Vergoten G. In Plant Polyphenols 2: Chemistry, Biology, Pharmacology, Ecology, Gross GG, Hemingway RW, Yoshida T (eds). Kluwer Academic/Plenum Publishers: New York, 1999; 527-544.

24. Press WH, Flannery BP, Teukolsky SA, VetterlingWT. Numerical Recipes in Pascal. The Art of Scientific Computing. Cambridge University Press: New York, 1989.

25. Monteiro C, Herv'e du Penhoat C. J. Phys. Chem. 2001; 105: 9827.

26. Cheek PJ, Lilley TH. J. Chem. Soc., Faraday Trans. 1988; 84: 1927.

27. Sivakama Sundari C, Balasubramanian D. Prog. Biophys. Mol. Biol. 1997; 67: 183.

28. Wu D, Chen A, Johnson CS Jr. J. Magn. Reson. A 1995; 115: 260. 29. Wiseman T,Williston S, Brandts JF, Lin LN. Anal. Biochem. 1989; 179: 131.

30. Sigurskjold BW. Anal. Biochem. 2000; 277: 260.

31. Tanner JE. J. Chem. Phys. 1970; 52: 2523. 